\title{
Spongiform Encephalopathy of Long Duration: A Family Study
}

\author{
G.P.A. RICE, D. W. PATY, M.J. BALL, R. TATHAM, and A. KERTESZ
}

SUMMARY: Seven members of a family succumbed to prolonged dementing illnesses. In two, whose dementia lasted 10 years, spongiform encephalopathy was found at autopsy. This duration of illness has not been a feature in other instances of familial Creutzfeldt-Jakob disease.

RÉSUMÉ: Sept membres d'une même famille sont décédés des suites de maladies démentielles prolongées. Chez deux patients, dont la démence dura 10 ans, une encéphalopathie spongiforme fut trouvée à l'autopsie. Une telle durée de maladie n'a pas été l'apanage des autres cas de Creutzfeldt-Jakob familiaux rapportés.

From the University Hospital and St. Joseph's Hospital, London University of Western Ontario Homewood Sanitarium, Guelph, Ontario.

Reprint requests to Dr. M.J. Ball, University Hospital, 339 Windermere Road. London, Ontario N6A 5A5, Canada.

\section{INTRODUCTION}

The clinical features of CreutzfeldtJakob disease (CJD) typically encompass a progressive dementing illness with myoclonus, signs of pyramidal, cerebellar and extrapyramidal dysfunction associated with characteristic electroencephalographic (EEG) changes. The disease is rapidly progressive, the mean duration of illness averaging 7.3 months (7.5 SD; range 1.5 to 55.0) (Masters et al., 1979).

We recently encountered a family in which 7 members succumbed to a slowly progressive dementing illness, lasting 5 - 10 years, in which motor and EEG findings were not typical of CJD. The clinical picture was more compatible with familial "Alzheimer's disease." Pathological study disclosed an unexpected finding of spongiform encephalopathy in 2 of the patients, and a limbic encephalitis in another (material for study was unavailable in the other 4).

Case III-8 (see arrow; figure 1): Clinical Features

The proposita, a 47 year old woman was well until 1969 when she developed diminished insight, compulsive eating and inappropriately gregarious and affectionate behavior. Her memory worsened, comprehension failed, and she gradually became an inadequate housewife. Within 3 years, placement within an institution was required. A year later, she was nearly impoverished of intelligible speech, capable of echolalia alone. A brief period of kleptomania was observed. She became completely disoriented and incontinent of urine and stool. Motor examination revealed only stereotyped movements. Deterioration continued and by 1976, she could no longer feed herself, and walking was possible only with assistance.

In May 1978 she was referred for further investigation. Apart from emaciation $(35 \mathrm{~kg})$ there were no other general findings. On neurological examination she was unresponsive to verbal command. Occasional monosyllabic sounds were uttered. Grasp, glabellar, palmomental, and sucking reflexes were brisk. Doll's eye manoeuvers evoked a full range of eye movements. Pupils measured $4 \mathrm{~mm}$ and reacted normally to light, and the fundi were normal. She did not respond to visual threat. Corneal reflexes were normal and facial movements were symmetrical. Fasciculations of the tongue were seen. She moved all four extremities spontaneously. Rigidity was diffuse and a flexion posture was preferred. Tendon reflexes were brisk, and both plantar responses were upgoing. She would not consistently withdraw to pain. Myoclonus was never seen. There was no startle response.

Routine biochemical and hematological indices, thyroid function, and B12 were normal, and VDRL and FTA-ABS were negative. CSF was clear, colorless and acellular; protein measured $16 \mathrm{mg} / \mathrm{dl}$ and glucose 63 $\mathrm{mg} / \mathrm{dl}$. Skull $\mathrm{x}$-rays were normal and CT Scan revealed profound atrophy of grey matter. Electromyography (EMG) revealed normal motor and sensory conductions, with no evidence for denervation. (Because of a marked chewing response on oral stimulation, needle EMG of the tongue was impossible). EEG revealed a grade I dysrhythmia. Brain biopsy was performed on $29 / 5 / 78$.

\section{III-8 Pathological Features}

The right frontal lobe biopsy on the 
proposita, processed for histology immediately after surgical removal, showed at the light microscopic level, mild but definite neuronal fall-out in focal distribution, particularly within cortical layers III and IV (Fig. 3a); and a mild, patchy gliosis in deeper cortex as well as superficial white matter, involving both microglia and fibrous astrocytes (Fig. 3b).

No leptomeningeal lesions, vascular changes, cellular inclusions, microglial nodules (shrubs) or perivascular inflammatory cuffs were present. Special stains failed to demonstrate any neurofibrillary tangles of Alzheimer or senile (neuritic) plaques. Occasional nerve cells appeared somewhat swollen, and others rather pyknotic (Fig. 3a).

Although neither the paraffin sections of formalin-fixed material nor the one micron Spurr embedded sections of gluteraldehyde fixed tissue showed any definite spongy lesions, electron-microscopic examination revealed frequent vacuolar swelling of many neuritic processes in the cortex (Fig. 4 a b c). While technical artifact could not be absolutely excluded, the finding within such vacuolated neurites of curled fragments of membrane, sometimes in multi-vesicular configuration (Fig. 4 d e), strongly supported our impression that this patient had a genuine spongiform encephalopathy of the type described by several authors (Bignami and Forno, 1970; Bubis et al., 1972; Gajdusek, 1972; Kidd, 1967).

The patient was likely one of those advanced cases in which the spongy change may be difficult to see by light microscopy (Daniel, 1970).

Masters and Richardson (1978) considered the absence of spongiform change did not preclude the diagnosis, since it may not be found in cases of exceptionally long clinical duration.

\section{III-6 Clinical Features}

At 38, this patient first developed memory loss, inappropriate speech and behavior, and recurrent depressions. Physical examination revealed only dementia. Pneumoencephalogram demonstrated marked atrophy, more prominent in the left temporal horn. Skull $\mathrm{x}$-rays, isotope brain scan, CSF and EEG were normal. From age 45, he required institutionalization. Compulsive eating and craving for sweets were transient features, but with progress of the dementia he became apathetic. He developed difficulty chewing and swallowing and aspirated, causing his death at 48 . Autopsy was performed.

\section{III-6 Pathological Features}

Paraffin sections on 31 glass slides were made available from tissues obtained at a medico-legal autopsy, as well as 10 paraffin blocks of cerebral samples. The basal ganglia showed only mild astrogliosis. Sections of parietal cortex showed severe loss of neurons, marked focal astrogliosis and lesser degrees of microglial hyperplasia involving both cortex and white matter, as well as a moderate degree of spongiform change through the middle cortical laminae. Sections of temporal lobe showed a similar but even more severe degree of neuronal fallout, astrocytic and microglial hyperplasia of the cortex, and gliosis of the white matter. A milder degree of spongiform change was noted in the temporal cortex. Leptomeninges and blood vessels of cortical samples were not remarkable, although around one small intra-cortical vein there was a focal perivascular cuff of plasma cells and lymphocytes. The laminar destruction of the cortex was especially prominent in layers 2, 3 and 6. Similar features were noted in the cingulate portion of the frontal cortex. Another tiny cuff of chronic inflammatory cells was noted around an arteriole in the corpus callosum.

Despite Bodian preparations, no senile (neuritic) plaques or neuro-

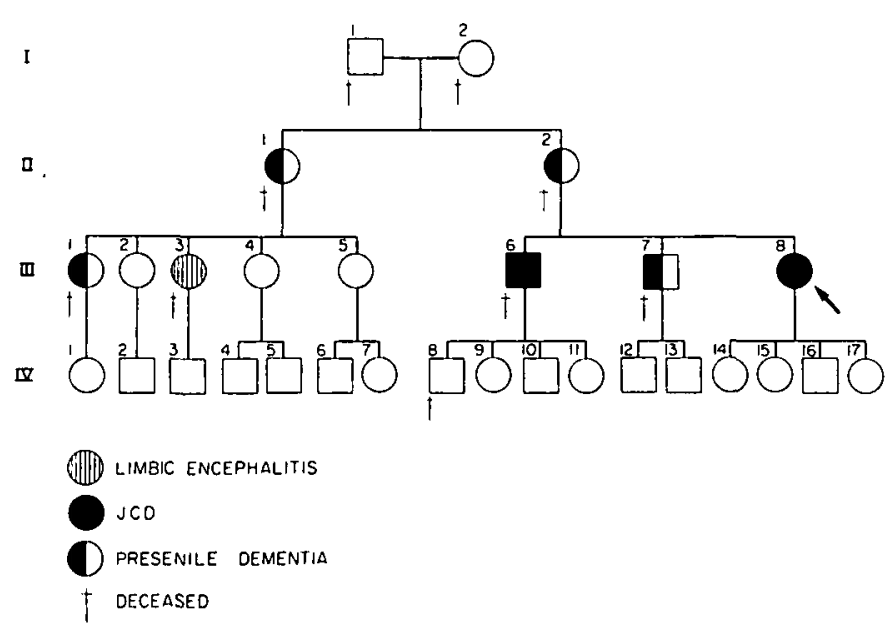

Figure I - Geneology of Family W.

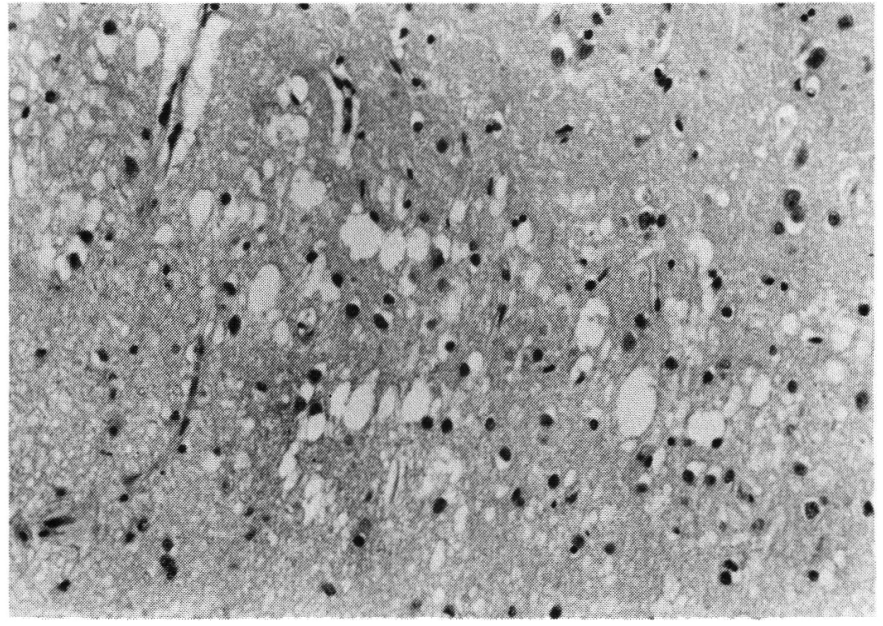

Figure 2 - Photomicrography of parietal cortex of patient III-6 showing neuronal loss, microglial hyperplasia, and significant spongiform stage in the middle cortical laminae. (paraffin section, hematoxylin and eosin stain, original magnification 625.) 

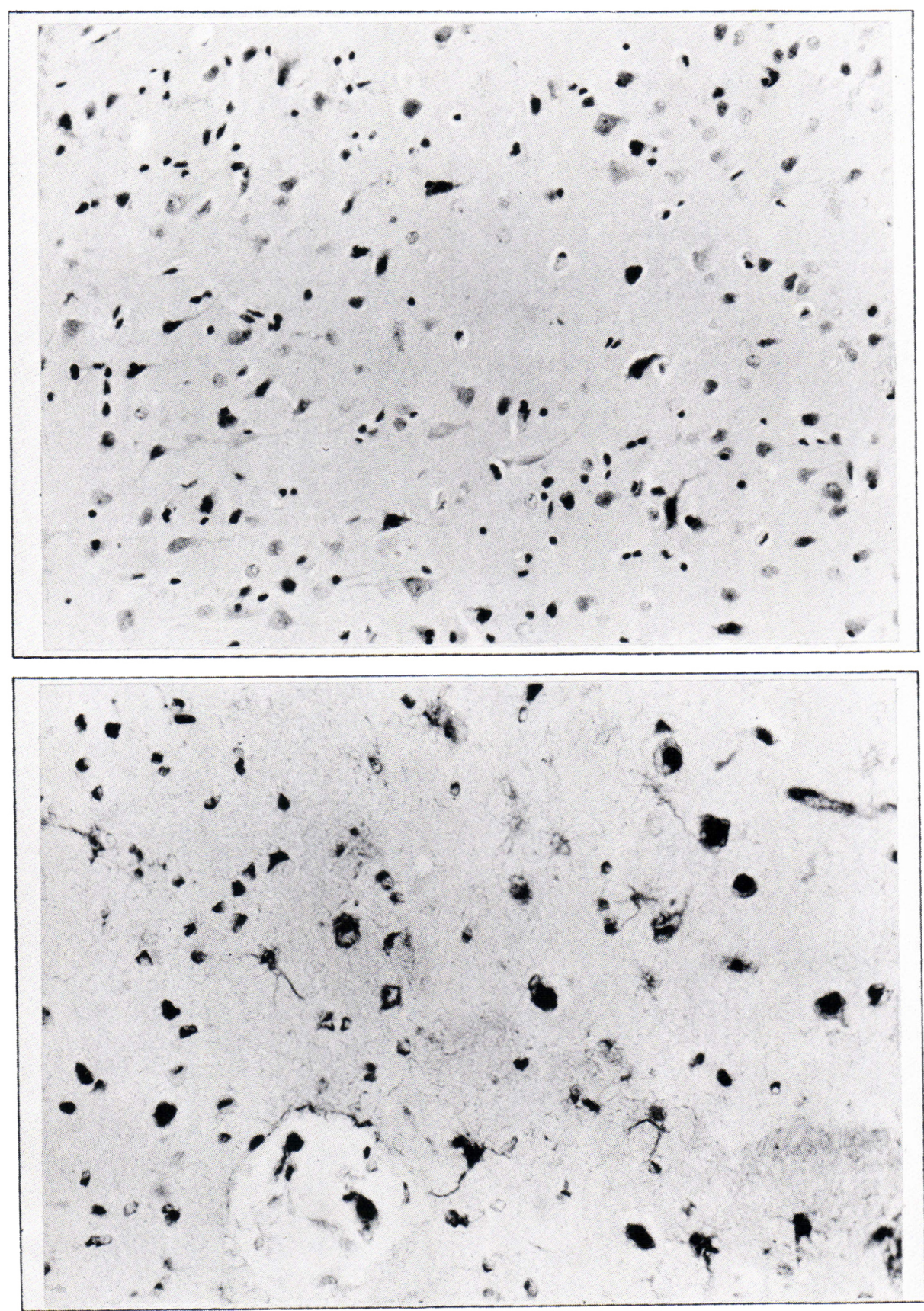

Figure 3 - Photomicrographs of parietal cortex of the proposita (111-8) revealing prominent neuronal fallout, especially in layers III and IV (figure "a" above; hematoxylin and eosin; magnification 200) and mild patchy gliosis involving microglia and fibrous astrocytes (figure "b" below; PTAH; magnification 400).

fibrillary tangles of Alzheimer could be seen in any of these sections, nor were there any granulovacuolar degeneration or rod-like bodies of Hirano. Sections of the mid and posterior portions of the hippocampus were not available.

Samples of the mid-pons, the medulla oblongata and the cervical spinal cord showed some moderate patchy demyelination and gliosis of the corticospinal fibers in the basis pontis, more prominent in the medullary pyramids, and especially in the lateral and ventral corticospinal tracts of the cervical cord. Mild neuronal loss and gliosis were noted in both anterior horns, and a small glial knot in one lateral column of the cord. The cerebellar samples were not remarkable.

There was thus no histological evidence on which to base a diagnosis of Alzheimer's disease, or any of the usual hereditary neurological disorders. Although certain histological features could have been consistent with the end stage of a previous necrotizing encephalopathy, possibly viral in nature, no cellular inclusions were seen nor was the degree of perivascular cuffing and microglial nodule formation as prominent as is usual to support a viral process.

On the other hand, the striking degree of spongiform degeneration affecting the parietal and temporal cortex (Fig. 2) was highly suggestive of the spongiosus seen in CreutzfeldtJakob disease. The neuropathological findings, including the pyramidal tract degeneration, are not dissimilar to the description of three family members having "spastic pseudosclerosis" (cortico-pallidospinal degeneration) by Davison and Rabiner (1940) who considered this a type of CreutzfeldtJakob disease.

Regrettably, wet tissue was no longer available from this central nervous sytem, and our attempt at electron-microscopic examination on some of the paraffin block material did not provide sufficient definition to prove conclusively the nature of the spongy changes. Nevertheless, we considered this to be an example of a spongiform encephalopathy.

\section{III-3 Clinical Features}

At 46 , this previously well patient developed an insidious loss of higher cortical function, associated with loss of motivation. Neither the tempo of the deterioration nor the reports of detailed neurological assessment are available. PEG revealed frontal atrophy. CSF, EEG and skull $x$-rays were normal. She died at 56 and an autopsy was performed.

\section{III-3 Pathological Features}

Paraffin sections were available from brain tissues removed during an autopsy in a state mental hospital. 


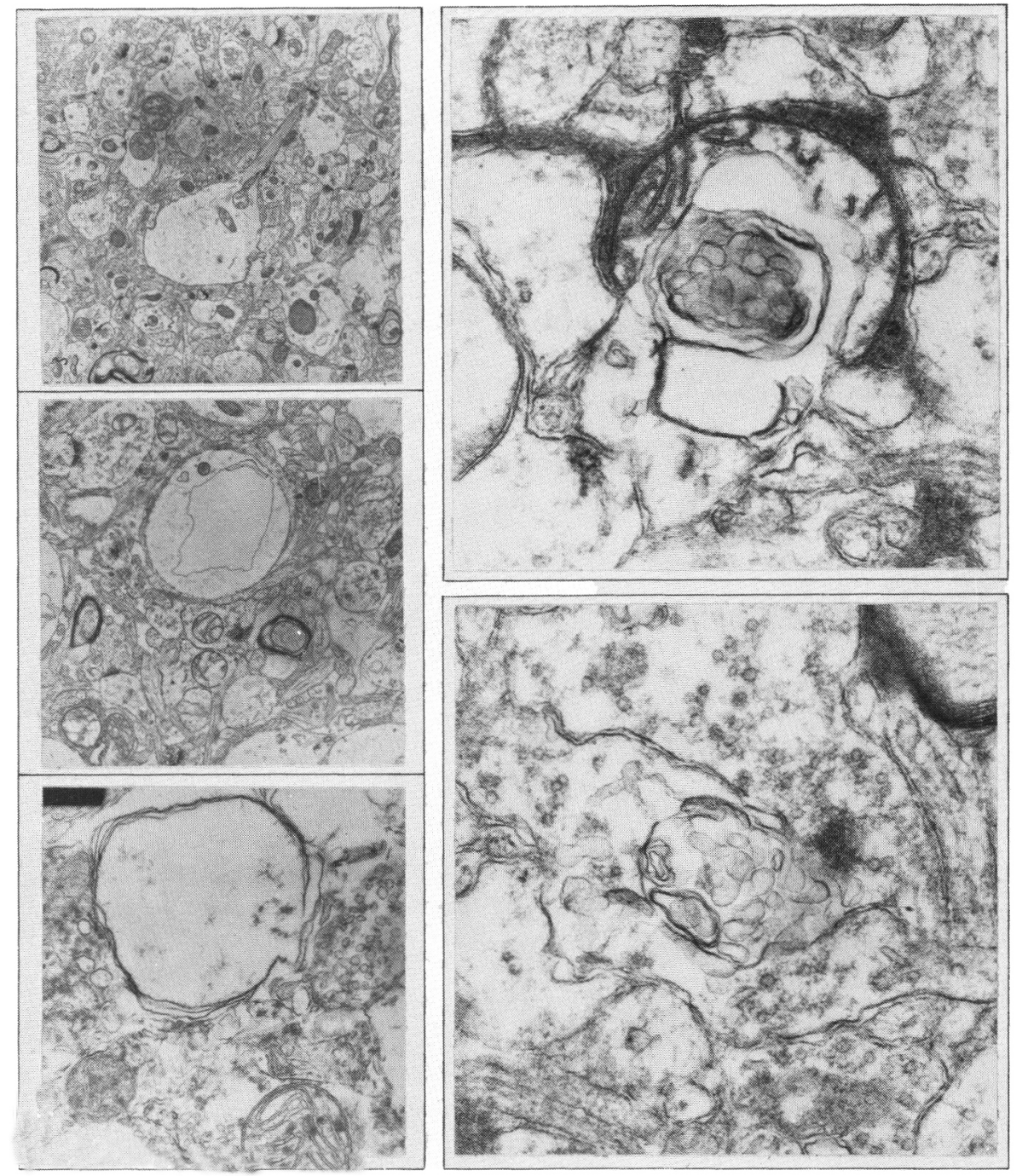

Figure 4 - Electron micrographs from the proposita (III-8) revealing frequent vacuolar swelling of many neuritic processes (4 a, b, c, left; magnification 4200) and within which were curled membrane fragments, sometimes in multi-vesicular configuration ( $4 \mathrm{~d}$, e; right; magnification 28,000).

Samples included cerebral cortex and subcortical white matter, striatum, thalamus, brainstem, cerebellum and spinal cord. All gyri of the temporal lobe, surrounding a markedly dilated horn of the lateral ventricle, showed extreme cortical atrophy due to severe neuronal loss and intense astrogliosis. Prominent astrocytic reaction was also seen in the white matter. Several large subependymal veins were surrounded by thick cuffs of chronic inflammatory cells, chiefly lymphocytes. The leptomeninges were not remarkable. The neuronal loss and gliosis were most severe in the anterior portions of the temporal lobe, especially the hippocampal region, with less affliction in the posterior hippocampus, where relatively well preserved pyramidal neurons showed no granulovacuolar degeneration, no Pick inclusions, and no Hirano bodies. All sections of basal ganglia were normal, except for a tiny perivascular cuff of lymphocytes in the lateral thalamus. Additional samples of cerebral cortex including the motor strip of the precentral gyrus and the orbital surface of the frontal lobe showed no lesions. Sections of brain- stem were not remarkable. A rare perivascular cuff was seen in one cerebral peduncle. Cerebellum and sections of cervical, thoracic, and lumbar cord were within normal limits. Silver stains failed to demonstrate any senile (neuritic) plaques or neurofibrillary tangles of Alzheimer in any of the cortical samples.

The features were considered typical for the end stage of an encephalitis which in its earlier, acute phase had apparently had its major effect on the temporal lobes, especially anterior portions. Our working pathological diagnosis was, therefore, a so-called "limbic encephalitis". The most likely etiological agent was a Herpes virus, although no classical microglial "shrubs" were seen nor were there any inclusion in the material available to us.*

\section{III-I Clinical Features}

At 41 years, this patient, maternal first cousin to the proband (Fig. 1) developed gradual memory loss, progressive apathy, and an uninhibited personality prone to vulgarity and inappropriate behavior. Within three years institutionalization was required. Over five more years she continued to deteriorate with progressive flattening of affect, loss of urinary and fecal continence, restriction of language and loss of all cognitive function. She remained ambulatory until her last year when she was virtually bedridden and required to be fed with assistance. She had great difficulty swallowing and speaking. Details of her neurological exam were unavailable. CSF and EEG were normal. She died of unknown causes at 49; autopsy was not performed.

\section{III-7 Clinical Features}

At the age of 43 , this successful lawyer developed a gradual dementing illness. At the onset he was frequently hospitalized for severe depressions, but progressively lost higher cognitive functions, and required institutional care within 2 years. Compulsive eating was a major feature. Detailed neurological assessments failed to reveal any abnormality except the dementia.

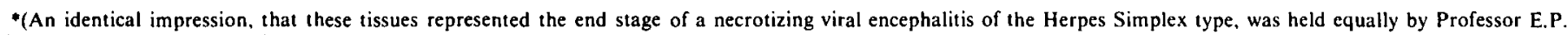
Richardson. Jr., who also reviewed these slides.) 
Pneumoencephalography revealed moderate frontal atrophy. Skull $x$-rays, EEG and CSF were normal.

$\mathrm{He}$ died five years later at 48 ; autopsy was not performed.

\section{II-2}

Little is known about this patient. She died at 48 in a mental hospital after several years' deterioration in personality and memory. Alzheimer's disease was her clinical diagnosis.

\section{II-I}

Little is known about this woman. She died of a "cerebral hemorrhage" at 47 years, after a seven year, gradual deterioration in cognitive function punctuated by profound behavioral aberrations. Autopsy was not performed.

\section{DISCUSSION}

The proposita developed a 10-year progressive dementing illness. A similar course was pursued by 6 other family members. The durations of the dementing illnesses average approximately 8 years. (There may be some error in duration of dementia in the earliest generation whose histories were pieced together from institutional records and family memory.) Fasciculations, myoclonus, and striking EEG abnormalities were not features. The tempo of the dementia in all cases was gradual. Motor deterioration in the proposita was a late feature, and was absent in the others. Though the proposita may have had fasciculations of her tongue suggestive of CJD, these could not be studied electromyographically because of her exaggerated chewing response on oral stimulation. Abnormal anterior horn cell findings were absent elsewhere.

The family bore more resemblance to familial Alzheimer's disease (AD). The finding of spongiform encephalopathy both in the proposita and in her brother was unexpected. Resolving this diagnosis with the clinical features is possible, but certain features are unusual. Sporadic cases of CJD of such duration have been described (Kirschbaum, 1968), though this is far longer than the mean duration reported in 94 patients with transmis- sible CJD (mean 7.3 months; 7.5SD, range 1.5 to 55.0) (Masters et al., 1979). Such duration has not been a feature in familial CJD. As well, motor and EEG findings of CJD seem less well represented in this family.

The clinical resemblance of these cases to familial Alzheimer's disease (AD) despite pathological identification of CJD in 2 of them prompts speculation about a possible relationship between the two diseases, as has been suggested by several observers:

(1) Two patients in whom the diagnosis of familial AD was established both clinically and pathologically have had a successful transmission of a "slow" viral agent to squirrel monkeys, who subsequently developed a spongiform encephalopathy (Traub et al., 1977). In one patient (A.Y.) there were 5 close family members with the disease in two generations; in the other, both the patient's father and sister had died of "presenile dementia". The transmitted disease in the animal model was clinically and pathologically typical of subacute spongiform encephalopathy, and did not have the histological features of $\mathrm{AD}$, the parent disease. Some mild spongiform change was later noted in the original biopsy material from one of these two patients, who remains alive 9 years later (Rewcastle et al., 1978). More than 30 attempts to transmit such a disease using brain tissue from sporadic Alzheimer cases have been unsuccessful.

(2) Geographic clustering of some cases of CJD and $A D$ has heightened speculation that exposure to some common environmental factor may be of importance (Mayer et al., 1977).

(3) Rosenthal et al., (1976) described a family with an increased incidence of a peculiar neurological illness. One member developed CJD, three others suffered chronic dementias, and 14 others developed various motor system abnormalities without dementia. The neurological disease followed autosomal dominant inheritance. The heterogeneity of these diseases and their inheritance pattern in the family suggested that the suscep- tibility to neurological disease was a genetic trait. This and other similar reports must temper our speculation that all demented patients in this family had CJD.

In both familial $A D$ and familial CJD, autosomal dominant inheritance is suggested. This pattern is followed in this family, but note is made of the possibility of vertical transmission, though this is not a general feature in the familial cases (Masters et al., 1979).

The burden of the hereditary nature of this illness falls upon members of the youngest generation, now nearing their third or fourth decade. They have collectively decided to defer reproduction until more is known about the nature of this illness. Looking for genetic markers that might identify the tendency to dementia in this family, we have performed histocompatibility typing on the remaining members. There was sharing of assigned haplotypes between III-6, III-7, and III-8 (HLA $3 / 8$ ). Follow up of the youngest generation will be necessary to determine the significance of this. To prove further that the spongiform change in our index case is secondary to a transmissible virus agent primate inoculation has been performed on biopsy material. We await results of these studies.

\section{ADDENDUM}

The proband has expired since the preparation of this manuscript. Necropsy has revealed an atrophic, hydrocephalic brain with the brunt of the cortical shrinkage in frontal and temporal lobes. The total absence of neurofibrillary tangles, senile plaques, and granulovacuolar degeneration is notable. Pick and Lewy bodies are nowhere present.

The striking light microscopic features are intense neuronal loss, astrogliosis, and laminar spongiform change, but the latter is confined to the superficial neocortical layers. Corticospinal tract degeneration and motor neuron depopulation are noted in brain stem and spinal cord. Electronmicroscopy will be discussed in another paper (Ball, M. J. "Features of Creutzfeldt-Jakob disease in Brains of Patients with Familial Dementia of the Alzheimer Type," Can. J. Neur. Sci. Feb. 1980) 


\section{ACKNOWLEDGEMENTS}

Ms. M. Stokes, Mrs. E. Hunter and Mr. J. Hewitt prepared the tissue for light and electron-microscopy. Dr. B. Bergman provided some of the tissue.

\section{REFERENCES}

BIGNAMI, A. and FORNO, L. S., (1970) Status spongiosus in Jakob-Creutzfeldt disease: Electron-microscopic study of a cortical biopsy. Brain 93: 89-94.

BUBIS, J. J., GOLDHAMMER, Y, and BRAHAM, J., (1972) Subacute spongiform encephalopathy. Electron microscopic studies. J. Neurol. Neurosurg., Psychiat. 35: 881-887.

DANIEL, P. M., (1970) Creutzfeldt-Jakob disease: J. Clin. Path. 25, Supp. 6: 97-101.

DAVISON, C. and RABINER, A.M., (1940) Spastic pseudosclerosis. Arch. Neurol. Psychiat. 44: 578-598.
GAJDUSEK, D.C., (1972) Spongiform virus encephalopathies, J. Clin. Path., 25: Supp. 6, 78-83.

GAJDUSEK, D.C., (1977) Unconventional viruses and the origin and disappearance of Kuru. Science 197: 943-960.

KIDD, M., (1967) Some electron-microscopal observations on status spongiosus. Acta. Neuropath. Supp. III: 137-144.

KIRSCHBAUM, S.R., (1968) Jakob-Creutzfeldt disease. New York, American Elsevier Publishing Co. Inc.

MASTERS, C.L., HARRIS, J.D., GAJDUSEK, D.C. et al., (1979) Creutzfeldt-Jakob disease: Patterns of worldwide occurrence and the significance of familial and sporadic clustering. Ann. Neurol. 5: 177-188.

MASTERS, C.L. and RICHARDSON, E.P., (1978) Subacute spongiform encephalopathy (Creutzfeldt-Jakob disease). Brain 101: 333-344.
MAY, W. W., ITABASHI, H.H.. DEJONG, R. N., (1968) Creutzfeldt-Jakob disease. Arch. Neurol. 19: 137-149.

MAYER, V., OROLIN, D. and MITROVA, E., (1977) Cluster of Creutzfeldt-Jakob disease and Presenile Dementia. Lancet 2: 256.

REWCASTLE, N.B., GIBBS, C.J., GAJDUSEK, D.C., (1978) Transmission of Alzheimer's disease to primates. VIII International Congress of Neuropathology, Washington, D. C.

ROSENTHAL, N.P., KEESEY, J., CRANDALL, B., ET AL, (1976) Familial Neurological Disease Associated with Spongiform Encephalopathy. Arch. Neurol. 33: 252-259.

TRAUB, R., GAJDUSEK, D.C., GIBBS, C. J., (1977) Aging and Dementia. Kinsbourne and Smith, Eds. (Spectrum, Flushing, N.Y.) pp. 9 l-146. 